\title{
O currículo de matemática dos anos iniciais do ensino fundamental na base nacional comum curricular (BNCC): os subalternos falam?
}

\author{
Maria José Costa dos Santos*
}

\begin{abstract}
Resumo
Neste texto, objetivamos analisar a partir da Base Nacional Comum Curricular-BNCC, as reformas curriculares propostas pelo governo, e a viabilização dessas reformas para a melhoria do ensino de matemática nos anos iniciais do ensino fundamental. Para tanto, refletimos sobre os objetos de conhecimento, o direito de aprender, a participação dos professores nas políticas públicas de elaboração e implementação da BNCC. As análises apontam que há incongruência entre a BNCC e a voz dos professores. Para a superação dessa problemática, propomos que as políticas públicas educacionais sejam mais orientadoras e menos reguladoras.

Palavras-chave: Currículo; Matemática; BNCC; Política educacional.
\end{abstract}

\section{The mathematics curriculum of the early years of elementary school on the common national curricular basis (BNCC): the subalterns speak?}

\begin{abstract}
In this text, we aim to analyze from the National Curricular-BNCC Common Base, like curricular reforms proposed by the government, and a viabilization of reforms for the improvement of mathematics teaching in the initial years of elementary education. To do so, we reflect on the objects of knowledge, the right of learning, the participation of the teachers in the public policies of elaboration and implementation of the BNCC. As analyzes show that there is incongruity between a BNCC and a voice of teachers. To overcome this problem, we propose how educational public policies are more guiding and less regulatory.
\end{abstract}

Keywords: Curriculum; Mathematics; BNCC; Educational politics.

\section{Para início de conversa...}

A Matemática constitui uma área de conhecimento que para alguns é complexa, mas quando trabalhada de forma contextualizada e interdisciplinar, se apresenta como um campo curricular fascinante, desse modo, democratizar sua aprendizagem na escola deve ser o papel do professor (BRASIL, 1997). Nesse sentido, este trabalho apresenta uma discussão sobre algumas questões curriculares que envolvem a Base Nacional Comum Curricular-BNCC (BRASIL, 2017) a partir de uma reflexão sobre os objetos de conhecimento e conteúdos de matemática nos anos iniciais do ensino fundamental.

Refletimos sobre a relação da BNCC com o cumprimento da meta 7 do Plano Nacional de Educação-PNE (2014-2024), assim como a melhoria da qualidade da Educação Básica, e ainda, sobre a meta 15 do PNE, que propõe a garantia de política nacional de formação dos profissionais da educação no que se refere ao Art. 61 da Lei $n^{\circ}$. 9.394/96 (BRASIL, 1996) assegurando que todos os professores e professoras da educação básica possuam formação específica de nível superior, obtida em curso de licenciatura na área de conhecimento em que atuam.

"Endereço eletrônico: mazzesantos@ufc.br
Embora essas reflexões estejam presentes no debate sobre a qualidade de educação, a falta de domínio dos conteúdos por parte de alguns estudantes - especificamente aqui nos referimos aos estudantes dos anos iniciais do ensino fundamental - gera uma aprendizagem de matemática repleta de falhas conceituais, lacunas, a qual fica evidenciada nos resultados das edições das avaliações externas, seja em âmbito local, nacional, seja em esfera internacional.

De acordo com a Lei de Diretrizes e Bases da Educação Nacional - LDBEN (BRASIL, 1996) são os cursos de Pedagogia que representam o espaço de formação para a docência nos anos iniciais do ensino fundamental, e portanto, questões sobre: (a) formação docente; (b) avaliação; e, (c) currículo, devem ser bem pensadas nesse espaço, pois é esse profissional que leciona a matemática nessa etapa da educação básica. Assim, para o enfrentamento das demandas exigidas, consideramos necessário discutir a $\mathrm{BNCC}$, mais especificamente, os conteúdos de matemática, e a participação do professor na construção desse documento que tem como objetivo redimensionar a proposta curricular nas escolas.

Para tanto, apoiados nos pressupostos metodológicos que apontam Lakatos e Marconi 
(1991), sobre a pesquisa qualitativa, buscamos compreensões sobre os documentos da BNCC e do PNE, especificamente, a cerca dos objetos de conhecimento propostos para a matemática dos anos iniciais do ensino fundamental. Essa investigação, seguiu a concepção de uma pesquisa empíricaexploratória, e nessa perspectiva, a investigação consistiu num ensaio teórico-especulativo, sobre o qual procuramos articular uma série de perguntas sobre a temática, a partir de um marco interpretativo geral, por meio do qual foi possível deduzir hipóteses explicativas. Os autores caracterizam esse tipo de pesquisa, como um processo científico de investigação que possibilita ao pesquisador formular questões, com três finalidades: levantar hipóteses, aumentar a familiarização do pesquisador com objeto de pesquisa, modificar ou clarificar conceitos. E com esse entendimento que apresentamos em que medida os objetos de conhecimento da BNCC, atendem com qualidade a área de matemática, nos anos iniciais do ensino fundamental, com foco no currículo, na formação docente e nas avaliações internas e externas.

A fim de proporcionar maior clareza ao nosso objeto de estudo nos amparamos nas pesquisas que tratam sobre (a) formação do professor: voz e conhecimento; (b) currículo de matemática; e, (c) avaliações, relacionando essas temáticas com as políticas públicas de educação, observando a participação do professor na discussão sobre essas temáticas, especialmente na construção da BNCC. Para tanto, é necessário tecermos redes intelectivas entre essas temáticas, a fim de apresentarmos a BNCC à comunidade escolar, além de discutirmos as reformas educacionais curriculares com vistas às reformas na LDBEM, $n$. ${ }^{\circ}$ 9394/96, e expormos breves considerações sobre o PNE e as políticas públicas em nível nacional.

Este texto está organizado em seções temáticas cuja a intenção é apresentar a BNCC, a partir dos objetos de conhecimento, o direito de aprender, para enfim chegarmos a identificação da voz do professor - aqui tomados por subalternos, para a tradução, interpretação e implementação das políticas públicas curriculares, na escola.

\section{O currículo e o professor}

Sabemos que uma das finalidades principais da Base Nacional Comum Curricular-BNCC é o cumprimento da meta 7 do Plano Nacional de Educação-PNE (2014-2024), a qual visa a melhoria da qualidade da Educação Básica - (aumentar a matrícula e melhorar a aprendizagem). Nesse contexto, vale o destaque da meta 15 , que

propõe garantir, em regime de colaboração entre a União, os Estados, o Distrito Federal e os Municípios, no prazo de 1 (um) ano de vigência deste PNE, política nacional de formação dos profissionais da educação de que tratam os incisos I, II e III do caput do art. 61 da Lei $\mathrm{n}^{\circ}$ 9.394, de 20 de dezembro de 1996, assegurando que todos os professores e professoras da educação básica possuam formação específica de nível superior, obtida em curso de licenciatura na área de conhecimento em que atuam (BRASIL, 2014, p. 12).

Como marco essencial para a melhoria da educação.

Na discussão sobre a BNCC, vimos que a sociedade e os educadores demonstram preocupação com a [re]organização curricular, e a estruturação de uma Base Nacional Comum Curricular (BNCC). Para Apple (2002a, p. 59-60) "o currículo é parte de uma tradição seletiva, (...) da visão de algum grupo acerca do que seja conhecimento legítimo (...) tudo isso está diretamente relacionado à maneira como o domínio e subordinação são produzidos e alterados (...)".

Indubitavelmente, as políticas públicas que envolvem o currículo escolar, e as implicações dessa discussão em nível nacional, mais efetivamente a partir da promulgação da Lei de Diretrizes e Bases da Educação (LDBEN) $\mathrm{n}^{\circ}$. 9.394/96, ganham maior força e adesão com a Lei n. ${ }^{\circ} 13.005$, de 25 de junho de 2014, que promulga o Plano Nacional de Educação-PNE (BRASIL, 2014). Mas quem tem voz nesse debate? Quem tem o poder para ser ouvido? Foucault (1979) nos lembra que se quisermos compreender como funciona o poder, basta que olhemos para as margens, para observarmos a luta daqueles que foram relegados à condição de os outros por poderosos grupos da sociedade.

Mas o que é currículo? O termo curriculum tem sua raiz no latim e significa o curso, a rota, o caminho da vida ou das atividades de uma pessoa ou grupo de pessoas (SACRISTÁN, 2013). De acordo com a origem da palavra, podemos afirmar que o currículo direciona a vida dos sujeitos, e que é relevante e de imenso significado para a comunidade escolar, pois dependendo de como os conhecimentos são organizados, apresentados, tem o poder de nortear, mudar ou parar a vida dos estudantes e professores. Nessa perspectiva, para 
D'Ambrosio

Currículo é o conjunto de estratégias para se atingir as metas maiores da educação. $\mathrm{O}$ currículo tem como componentes solidários objetivos, conteúdos e métodos. O solidário significa que não se pode alterar um dos componentes sem que se alterem os outros dois (D'AMBROSIO, 2011, p. 11).

Freire (1987) que é uma das grandes personalidades intelectuais e responsável também pela discussão sobre o currículo, fala sobre a vida do indivíduo, como sujeito epistêmico e que deve passar por uma educação pautada no diálogo crítico. Portanto, seja o currículo formal ou informal, ele deve proporcionar ao sujeito uma formação humanística, crítica voltada para a cidadania. O autor destaca ainda que devemos pensar sobre o currículo, para além dessas denominações e destaca que é importante abandonar o tecnicismo e partir para um currículo multifacetado.

Nossa compreensão de currículo, não se limita à seleção política, de conteúdos considerados válidos, de comportamentos considerados necessários a partir de regras postas em documentos oficiais, considerados importantes, e que são elaborados em um determinado momento histórico, carregado de ideologias. Influenciados por Freire chegamos a uma ideia de currículo que pressupõe uma visão de superação de algo que deve ser formal, cumprido no âmbito escolar, mas que deve estar em constante construção/reconstrução para atender às necessidades do sujeito. Sobre isso, Santos e Matos (2017, p. 6) lembram que "O currículo deve ser dinâmico e deve principalmente, atender à realidade do aluno, deve dar total autonomia ao professor, para que este não sufoque sua criatividade em meio a um currículo congelado e engessado (...)".

Freire (1987, p. 30) destaca que "o professor contemporâneo é um organizador do currículo, e nesse sentido deve viver inteiramente o seu tempo, conviver com o outro, ter consciência e sensibilidade acerca dos conteúdos e da educação". Para o autor, o professor deve ser um tradutor do conhecimento diante do aluno, além de ser um construtor de sentidos, e como um organizador do currículo, é também um organizador da aprendizagem.

Um professor nessa perspectiva, precisa passar uma formação mais crítica. A esse respeito, Nóvoa (1999, p. 13) destaca que "a formação de professores vai do excesso dos discursos à Pobreza das Práticas", mas informa que não sugere com essa reflexão uma oposição entre discursos e práticas, como se estivéssemos diante de dois mundos distintos, todavia o que ele espera é "demonstrar de que forma os discursos induzem comportamentos e prescrevem atitudes razoáveis e correctas (e viceversa)". (NÓVOA, 1999, p. 13, destaques do autor).

Certamente, essas questões surgem da disputa no cenário das políticas públicas sobre formação docente e currículo. Lopes (2012) diz que nos mais diferentes contextos nos quais as políticas públicas curriculares se desenvolvem, há indícios de enfoques instrumentais, às vezes inclusive com destaque, à tendência prescrita. Nessa perspectiva, Lopes e Macedo (2011, p. 42, destaque do autor) dizem que "seja o currículo escrito, falado, velado, ele é um texto que tenta direcionar o leitor, mas que o faz apenas parcialmente". Entretanto, o currículo produz sentidos, e assim, nos inclui, exclui, define nossa identidade e, por isso, precisa ser pensado como um instrumento de poder, que transforma, interfere no nosso modo de ser, pensar, e determina nossas práticas, nosso discurso, nosso método.

Apesar do poder das políticas públicas sobre o currículo oficial e a relação disso com a seleção de conteúdos, ressaltamos a importância de se pensar o sentido de currículo, a partir da observância às matrizes curriculares regional/local, e o cuidado com a seleção de conteúdos matemáticos e os objetos de conhecimento apontados pela BNCC.

\section{Os objetos de conhecimento e o direito de aprender}

É relevante apresentar a BNCC e algumas reflexões sobre os objetos de conhecimento que influenciarão diretamente nos processos de ensino e de aprendizagem na educação básica, especialmente, no ensino fundamental, acerca dos conteúdos de matemática. Sobre o conhecimento matemático a BNCC considera que

(...) é necessário para todos os alunos da Educação Básica, seja por sua grande aplicação na sociedade contemporânea, seja pelas suas potencialidades na formação de cidadãos críticos, cientes de suas responsabilidades sociais (BRASIL, 2017, p. 221).

Os conteúdos apresentados na BNCC são organizados visando as muitas possibilidades de aparelhamento do conhecimento escolar em unidades temáticas, e cada unidade temática 
contempla um leque (maior ou menor) de objetos de conhecimento. Para D'Ambrosio (2011, p. 76) "a matemática escolar é o substrato formal de uma reunião de modelos do mundo real, originados de situações e problemas concretos", (...) a matemática tem muito a ver com o tempo e com o espaço, e a aquisição do conhecimento por meio do ensino, mostra claramente que esse ensino ainda é tratado segmentado em disciplinas, e sem nenhuma relação entre elas. Mas os diferentes campos que compõem a Matemática reúnem um conjunto de conceitos fundamentais que se articulam com equivalência, ordem, proporcionalidade, interdependência, representação, variação e aproximação.

A seguir, na figura 1, destacamos os objetos de conhecimento matemático do $2 .^{\circ}$ ano dos anos iniciais do ensino fundamental, presentes na BNCC. Escolhemos esse ano da etapa da educação básica, pois a $\mathrm{BNCC}$ informa que é nos dois primeiros anos do ensino fundamental, que a ação pedagógica deve ter como foco a alfabetização, garantindo amplas oportunidades e se articulando com as práticas diversificadas de letramento. (BRASIL, 2017).

FIGURA 1: Objetos de conhecimento matemático para o $2^{\circ}$ ano dos anos iniciais do ensino fundamental

\begin{tabular}{|c|c|}
\hline & tos de conhecimento \\
\hline Número & $\begin{array}{l}\text { Leitura, escrita, comparação e ordenação de números de até três ordens pela compreensão de } \\
\text { características do sistema de numeração decimal (valor posicional e papel do zero) } \\
\text { Composição e decomposição de números naturais (até 1000) } \\
\text { Construção de fatos fundamentais da adição e da subtração } \\
\text { Problemas envolvendo diferentes significados da adição e da subtração (juntar, acrescentar, separar, } \\
\text { retirar) } \\
\text { Problemas envolvendo adição de parcelas iguais (multiplicação) } \\
\text { Problemas envolvendo significados de dobro, metade, triplo e terça parte }\end{array}$ \\
\hline Álgebra & $\begin{array}{l}\text { cursivas } \\
\text { ação de elementos ausentes na sequência }\end{array}$ \\
\hline Geometria & $\begin{array}{l}\text { Localização e movimentação de pessoas e objetos no espaço, segundo pontos de referência, e indicação } \\
\text { de mudanças de direção e sentido } \\
\text { Esboço de roteiros e de plantas simples } \\
\text { Figuras geométricas espaciais (cubo, bloco retangular, pirâmide, cone, cilindro e esfera): reconhecimento } \\
\text { e características } \\
\text { Figuras geométricas planas (círculo, quadrado, retângulo e triângulo): reconhecimento e características }\end{array}$ \\
\hline $\begin{array}{l}\text { Grandezas e } \\
\text { Medidas }\end{array}$ & $\begin{array}{l}\text { Medida de comprimento: unidades não padronizadas e padronizadas (metro, centímetro e milímetro) } \\
\text { Medida de capacidade e de massa: unidades de medida não convencionais e convencionais (litro, } \\
\text { mililitro, } \mathrm{cm}^{3} \text {, grama e quilograma) } \\
\text { Medidas de tempo: intervalo de tempo, uso do calendário, leitura de horas em relógios digitais e } \\
\text { ordenação de datas } \\
\text { Sistema monetário brasileiro: reconhecimento de cédulas e moedas e equivalência de valores }\end{array}$ \\
\hline $\begin{array}{l}\text { Probabilidade } \\
\text { e estatística }\end{array}$ & $\begin{array}{l}\text { Análise da ideia de aleatório em situações do cotidiano } \\
\text { Coleta, classificação e representação de dados em tabelas simples e de dupla entrada e em gráficos de } \\
\text { colunas }\end{array}$ \\
\hline
\end{tabular}

Fonte: Adaptado da BNCC (BRASIL, 2017, p. 292-294).

As cinco unidades temáticas apresentadas, se correlacionam e orientam a formulação de habilidades a serem desenvolvidas durante os anos que compõem os anos iniciais do ensino fundamental. No que se refere à matemática, cada uma dessas unidades pode receber ênfase distinta, conforme o ano de escolarização, definindo os conteúdos, conceitos e processos. Essas reflexões sobre essas unidades temáticas, a partir dos objetos de conhecimento de matemática, nos levam a pensar sobre a qualidade de educação proposta pelo PNE e sua relação com a BNCC. E, nesse sentido, precisamos apreender o que é qualidade de educação e como os objetos do conhecimento da matemática dos anos iniciais, se conectam com os direitos de aprender.

Sobre qualidade da educação, entendemos que são elementos basilares: (i) garantia do direito de aprender para todos; (ii) currículo que atenda à realidade dos sujeitos da escola; (iii) professores 
valorizados, pais e alunos satisfeitos; (iv) infraestrutura adequada; e, (v) oportunidades educacionais equitativas, ofertadas pelos gestores, a todos. A qualidade de educação encontra amparo legal nas metas estabelecidas no PNE (2014-2024). A meta 7 , estabelece 36 estratégias, dentre elas destacamos a estratégia 7.12 que visa,

incentivar o desenvolvimento, selecionar, certificar e divulgar tecnologias educacionais para a educação infantil, o ensino fundamental e o ensino médio e incentivar práticas pedagógicas inovadoras que assegurem a melhoria do fluxo escolar e a aprendizagem, assegurada a diversidade de métodos e propostas pedagógicas, com preferência para softwares livres e recursos educacionais abertos, bem como o acompanhamento dos resultados nos sistemas de ensino em que forem aplicadas (BRASIL, 2014, p. 60).

E o direito de aprender? Com a BNCC, esse direito fica garantido na oferta de um currículo de base comum nacional, a partir do desenvolvimento das competências e habilidades, deixando claro o que todos devem aprender, pois "supõe a igualdade de oportunidades para ingressar, permanecer e aprender na escola, por meio do estabelecimento de um patamar de aprendizagem e desenvolvimento a que todos têm direito". (BRASIL, 2017, p. 16). Entretanto, entendemos que essa discussão sobre o que aprender, está envolta a um currículo como prática de poder. Nessa disputa curricular a BNCC se apresenta como

(...) um documento de caráter normativo que define o conjunto orgânico e progressivo de aprendizagens essenciais que todos os alunos devem desenvolver ao longo das etapas e modalidades da Educação Básica. (...) Referência nacional para a formulação dos currículos dos sistemas e das redes escolares dos Estados, do Distrito Federal e dos Municípios e das propostas pedagógicas das instituições escolares nesse sentido, espera-se que a BNCC ajude a superar a fragmentação das políticas educacionais, enseje o fortalecimento do regime de colaboração entre as três esferas de governo e seja balizadora da qualidade da educação (BRASIL, 2017, p. 7-8).

A ideia de um documento ser normativo, é suficiente para dar sentido à aprendizagem? Um currículo escolar, no que se refere à matemática, deve ir além da concepção que a BNCC oferece nos objetos de conhecimento e nas habilidades, distribuídos nas unidades temáticas: Números, Álgebra, Geometria, Grandezas e Medidas e Probabilidade e Estatística, pois os processos de ensinar e aprender devem contemplar uma noção contextual que envolve a abstração, para usar com competência os conhecimentos, e isso envolve capacidades essenciais, de: formular, empregar, interpretar e avaliar, mas também autonomia para criar.

A escola conseguirá desenvolver o que indica a BNCC? Isso vai depender, inclusive, de como essa política pública será traduzida, interpretada. Sobre isso Ball ( 2001) informa que atuação, interpretação, tradução e contexto são assim noções centrais para entender as políticas educacionais, e em muitos casos, recai sobre as escolas o papel de interpretação das políticas públicas educacionais que é de suma importância, e nesse contexto elas podem entusiasmar, deprimir ou afligir, mas é importante destacar que colocar as políticas públicas educacionais em prática é um processo sofisticado, criativo e complexo, cabendo a escola tomar as decisões observando, bem, a interpretação e atuação.

A BNCC aponta que a Matemática assume um papel fundamental de inclusão do sujeito, a partir de uma reflexão sobre sua cidadania e seu protagonismo na conscientização do direito de aprender. Para Morin (2003) essas reflexões não cabem em um programa, mas devem ser impulsionadas na formação do professor, e destaca a necessidade do emprego da inteligência geral, em que

Esse pleno emprego exige o livre exercício da faculdade mais comum e mais ativa na infância e na adolescência, a curiosidade, que, muito frequentemente, é aniquilada pela instrução, quando, ao contrário, trata-se de estimulá-la ou despertá-la, se estiver adormecida. Trata-se, desde cedo, de encorajar, de instigar a aptidão interrogativa e orientá-la para os problemas fundamentais de nossa própria condição e de nossa época (MORIN, 2003, p. 22).

Morin (2003), reforça que uma inteligência incapaz de perceber o contexto e o complexo planetário fica cega, inconsciente e irresponsável. Para Santos e Matos (2017, p. 6) "o currículo deve ser dinâmico e deve principalmente, atender à realidade do aluno, deve dar total autonomia ao professor, para que este não sufoque sua criatividade em meio a um currículo congelado e engessado (...)". Mas a BNCC ainda se apresenta 
disciplinar, e, apesar da disciplinaridade das ciências ter trazido as vantagens da divisão do trabalho, trouxe também o despedaçamento do saber.

Ainda sobre o direito de aprender, o texto da BNCC coloca o estudante como elemento responsável por sua própria aprendizagem, nessa perspectiva faz-se necessário lembrar o papel do Estado, pois de acordo com a Constituição FederalCF (BRASIL, 1988) Art. 205 a educação é um direito de todos, e um dever do estado.

A educação, direito de todos e dever do Estado e da família, será promovida e incentivada com a colaboração da sociedade, visando ao pleno desenvolvimento da pessoa, seu preparo para o exercício da cidadania e sua qualificação para o trabalho (BRASIL, 1988, p. 156 ).

O direito de aprender é fundamental, e a aprendizagem como qualidade deve ser a meta principal da escola, fomentada pelo governo. No Brasil, de acordo com nossa CF (BRASIL, 1988), a escola, o Estado, a família todos precisam garantir o direito de aprendizagem, e garantir que esse direito seja cumprido. Vale enfatizar que o papel do Estado é primordial, pois sem sua colaboração, para garantir recursos e condições dignas de trabalho para os professores, não é possível que a escola e pais sozinhos garantam a qualidade no ensino. Sobre essa basilar importância da educação, e, por conseguinte, do direito de aprender, Cury (2002) diz

O direito à educação parte do reconhecimento de que o saber sistemático é mais do que uma importante herança cultural. Como parte da herança cultural, o cidadão torna-se capaz de se apossar de padrões cognitivos e formativos pelos quais tem maiores possibilidades de participar dos destinos de sua sociedade e colaborar na sua transformação. Ter o domínio de conhecimentos sistemáticos é também um patamar sine qua non a fim de poder alargar o campo e o horizonte destes e de novos conhecimentos (CURY, 2002, p. 247).

A função da BNCC é também cumprir o artigo 210 da Constituição Federal-CF (BRASIL, 1988) que já previa a fixação de conteúdos mínimos, vejamos: Art. 210. Serão fixados conteúdos mínimos para o ensino fundamental, de maneira a assegurar formação básica comum $e$ respeito aos valores culturais e artísticos, nacionais e regionais. (BRASIL, CF, 1988). Considerando a data da promulgação da $\mathrm{CF}$, a $\mathrm{BNCC}$ demorou quase trinta anos (30) anos para ser elaborada, e em 2017, foi apresentada à sociedade, como um documento de caráter mandatório, que deverá reger o ensino e a aprendizagem em nível nacional por muitos anos, haja vista a lacuna temporal entre a publicação dos PCN à BNCC. Portanto, devemos ficar atentos aos direitos de aprendizagem e suas condições de execução no ambiente escolar.

$\mathrm{Na}$ tentativa de garantia dos direitos de aprender e da qualidade na educação, em 2012, o Ministério de Educação-MEC (BRASIL, 2012), elaborou um documento sobre esse tema, mas para Saviani $^{1}$ (2013) é um documento que articula as áreas curriculares em eixos estruturantes, mas não é um currículo, pois um currículo precisa ter conteúdos, objetivos e procedimentos de ensino. Assim, já em 2013, Saviani nos alertava que discutir um documento sobre direito de aprendizagem, sem melhorar as estruturas da escola, não fazia sentido, e ainda, reforçava que no Brasil, discutem-se e formulam-se documentos, mas não se atacam as raízes do problema, dentre elas, as péssimas condições de funcionamento das escolas, os baixos salários e a formação precária dos professores.

E a implementação da BNCC? Nos preocupa perceber que essa é uma luta pela hegemonia de determinados conhecimentos, defendidos pelos grupos idealizadores/elaboradores da BNCC, influenciada pela cultura dos dominantes, os colonizadores, e entregues aos dominados, os colonizados. E apesar de assegurar que o estudante adquira minimamente conteúdos globais e que esses conteúdos sejam úteis em sua vida, exclui, por exemplo, o conteúdo de história que passa a ser organizado segundo a cronologia dos fatos, para os historiadores isso trará enormes prejuízos à compreensão histórica por parte do aluno sobre os acontecimentos, além de privá-lo de uma visão mais ampla e crítica desses fatos.

Esse é um dos desafios que o Brasil enfrenta por ter uma diversidade muito grande, e somente um currículo multifacetado/multiculturalista poderia atender às expectativas de nossa realidade como nação. Pois um currículo nacional, para ter validade e eficácia, requereria também a criação de um tecido articulador social e intelectual inteiramente novo e intimamente vinculado ao conteúdo e à Pedagogia do currículo escolar. Entretanto, um currículo multiculturalista é uma ameaça aos interesses da direita(neoliberal). Mas a BNCC diz garantir que

$$
\text { (...) os direitos de aprendizagem sejam }
$$


assegurados a todos os alunos. Com efeito, a explicitação de competências - a indicação clara do que os alunos devem saber, e, sobretudo, do que devem saber fazer como resultado de sua aprendizagem - oferece referências para o fortalecimento de ações que assegurem esses direitos. (...) os objetivos de aprendizagem dos componentes curriculares estabelecidos pela BNCC para toda a Educação Básica visam à aprendizagem e ao desenvolvimento global do aluno. A superação da fragmentação radicalmente disciplinar do conhecimento, o estímulo à sua aplicação na vida real, o protagonismo do aluno em sua aprendizagem e a importância do contexto para dar sentido ao que se aprende são alguns dos princípios subjacentes à BNCC (BRASIL, 2017, p. 16-17).

Quem decide o que os alunos devem aprender em Matemática nos anos iniciais do ensino fundamental? Apple (2002a, p. 79) nos adverte que "na Inglaterra o debate é o mesmo, e que um currículo nacional é visto pela Direita como essencial para evitar o relativismo". Já Bernstein (1996) nos lembra que, quais quer que sejam as práticas pedagógico-curriculares orientadas para o mercado e as orientadas para o conhecimento, as atuais desigualdades de raça, sexo e classe provavelmente serão reproduzidas.

Dentre as muitas polêmicas que envolvem a BNCC que obrigatoriamente deverá ser seguida pelas escolas, nos deparamos com as vozes e conhecimentos que não foram contemplados, ou simplesmente excluídos. No entanto, queremos discursar a favor de uma Pedagogia crítica que leve em conta como as transações simbólicas e materiais do cotidiano fornecem base para se repensar a forma como as pessoas dão sentido e substância ética às suas experiências e vozes.

Os subalternos podem falar? As vozes dos professores da educação básica foram ouvidas durante o processo de elaboração da BNCC? Para o governo, a sociedade foi amplamente chamada para colaborar com a construção da BNCC, e no texto da $\mathrm{BNCC}$, informa que

sua formulação, sob coordenação do MEC, contou com a participação dos Estados, Distrito Federal e Municípios, depois de ampla consulta à comunidade educacional e à sociedade, conforme consta da apresentação deste documento (BRASIL, 2017, p. 14).

Existe uma relação de consequência, entre ser chamado a falar e ser ouvido? Asseveramos que para promover a equidade na educação, é preciso um currículo diferenciado, multiculturalista pensado pelos professores. Pois um documento de caráter normativo e de base nacional não atende as especificidades e diversidade cultural de um país continental de profundas desigualdades sociais, quanto o Brasil.

\section{O currículo escolar de Matemática: os subalternos falam?}

Existe uma luta de superação de um currículo conteudista que inviabiliza mudanças significativas na qualidade de ensino na escola. Vimos que é necessário um currículo com bases multiculturais e interdisciplinares, para a transformação social, apresentando a escola, como o espaço em que se aprende a aprender, a conviver $e$ a ser com e para os outros, contrariando um tipo de currículo que segrega. Pois é na escola que o currículo se torna terra fértil para propor mudanças ou simplesmente manter o status quo das relações microfísicas de poder que se estabelecem cotidianamente. Para Foucault (1979) "quanto mais escondido o poder estiver, mais eficaz o será, pois os dominados não perceberão a relação de dominação e assim não resistirão".

É importante discutirmos a (re)construção de um currículo que venha colaborar para constituição de novos paradigmas nos processos de ensino e de aprendizagem que direcionem a instituição escolar a ultrapassar a barreira do modelo de ensino conteudista, o qual exige desse professor uma mudança de postura, para que ele possa inovar nas práticas pedagógicas, escolher, com qualidade, suas metodologias, e novas formas de avaliação, tendo como um documento de referência, o currículo. Mas discutir currículo, não é uma ação didática de fácil aceitação, isso pressupõe quebrar paradigmas, superar modelos ultrapassados, transpor barreiras hegemônicas, mas principalmente, é necessário que o professor se predisponha às mudanças, e isso gera desafios e questões de ordem pedagógica, mas principalmente, de ordem política. Os subalternos podem falar?

O que se sabe é que a hegemonia pressupõe que se deve levar em conta os interesses e as tendências dos grupos sobre os quais ela deve ser exercida, e promover equilíbrio, conciliatório, ou seja, "o grupo dominante deve fazer sacrifícios" (APPLE; BURAS, 2008, p. 12). É fato que existe uma necessidade premente dos grupos dominantes sobre os dominados - eles querem convertê-los. O 
conhecimento do dominador tem mais valor que o conhecimento do dominado? Tem mais valor o conhecimento de quem?

A respeito disso Sagoyewatha apud Apple \& Buras (2008) nos faz refletir

Vocês levaram vários de nossos jovens para suas escolas. Vocês os educaram e ensinaram sua religião. Quando retornaram à sua família e à sua cor, não eram homens brancos e nem índios. As artes que aprenderam são incompatíveis com a caça e não se adaptam aos nossos costumes. Eles aprenderam coisas que são inúteis para nós (...). Talvez vocês pensem que nós somos ignorantes e desinformados(...). Vão, então, aos brancos. Desenvolvam sua moral e refinem seus hábitos - façam com que sintam menos vontade de enganar os índios (APPLE; BURAS, 2008, p. 141-143).

A fala acima, feita a mais de dois séculos nos remete a pensar sobre a luta de grupos dominados contra a dominação, principalmente, sobre questões culturais e educacionais. Nas discussões sobre currículo, algumas vozes são cerceadas, e não ouvidas, especialmente, na implementação das políticas públicas. No século XXI, ainda se luta por conhecimento e voz, mas a força dos subalternos ainda é tolhida. Quem são os subalternos na disputa pelo currículo? Historicamente, os subalternos, em 1700, eram os vassalos e camponeses, pessoas das classes mais baixa do exército. No início do século XX, Gamsci ${ }^{2}$ usava esse termo (como código) para indicar grupos oprimidos, como operários industriais, e camponeses, mas seus Cadernos, ao circularem nas décadas de 1960 e 1970, ratificaram o conceito de Gramsci sobre o subalterno, tanto nos estudos culturais, como em teorias e pesquisas críticas educacionais.

Apesar de compreender que a classe subalterna era oprimida, ele confiava que o poder, por muitas vezes era exercido mais por meio de consentimento, do que pela força, ou seja, as elites conseguiam com que o povo ratificasse seu conhecimento, sua voz, e, portanto, se submetessem a relações de poder desiguais. Gamsci (1981), entendia que poderia mudar o curso da história e engendrar as condições necessárias para uma experiência mais justa. (APPLE; BURAS, 2008).

As disputas educacionais entre grupos dominantes e subalternos para definir o que conta como conhecimento e para se apropriar de recursos políticos, econômicos, culturais e sociais em uma variedade de contextos educacionais, (em âmbito nacional e local), são reflexos de uma luta de poder que envolve a disputa sobre o currículo comum, currículo oficial, currículo cultural (subalterno). Assim, mesmo com as limitações das ações subalternas, conhecimento e voz - são objetos de luta dos educadores críticos contra relações de dominação e subordinação, e ao falarmos nos subalternos insurge uma discussão sobre diversos grupos submetidos a relações de poder desiguais. E sobre essas relações de poder desigual, Apple \& Buras (2008, p. 14) advertem que seja em salas de aula, seja em salas de reunião,

(...) universidades ou fundações -, cada espaço se caracteriza pela dinâmica do poder diferencial e pelas complexidades e contradições da identidade e da ação. Nas áreas do currículo, da política educacional e da reforma, lutas de todos os tipos ocorrem nos circuitos de produção, distribuição e recepção.

Podemos inferir que a política que envolve produção, distribuição e recepção do conhecimento curricular é intensa e complexa, e que as disputas pelo currículo - sobre quais experiências serão representadas como válidas ou qual língua ou história será ensinada - são constantes. Tais conflitos são presentes, à medida que multiculturalistas de todas as linhas protestam por maior heterogeneidade no currículo. (APPLE; BURAS, 2008).

As lutas pela hegemonia curricular concentram-se na produção e na distribuição do conhecimento, e nas escolas se presencia um foco crescente em como as próprias funcionam como locais de recontextualização do corpus formal do conhecimento. No entanto, é fato que o conhecimento nunca é transmitido de forma fácil, seja: (a) currículo para o professor; (b) do livro didático para o aluno; ou mesmo, (c) do professor para o aluno. Nesse sentido, para Apple \& Buras (2008, p. 31)

[...] o currículo oficial sempre é reconstruído no nível da recepção, à medida que professores e alunos entram no interminável processo cotidiano de compreensão, resistência e ensino e aprendizado. [...] nenhum dos conflitos [...] ocorre em um solo nivelado.

A discussão apresentada por Apple \& Buras (2008) se passa na Inglaterra, mas de forma globalizada, e, portanto, nos apoiamos nessas 
reflexões, porque aqui no Brasil essa discussão acontece de forma bem semelhante, como exemplo, destacamos as políticas públicas de currículo, em 1997, com os Parâmetros Curriculares NacionaisPCN e, em 2016, a Base Nacional Comum Curricular-BNCC, as quais podem nos ajudar a entender melhor a dinâmica do poder, as apostas e as possibilidades democráticas na elaboração do currículo no Brasil.

Apple (2008, p. 218) destaca uma visita feita ao Brasil: "Durante umas das vezes em que estive no Brasil trabalhando com Paulo Freire, lembro-me de ele me dizer repetidas vezes que a educação deve começar no diálogo crítico". E nisso, o autor reforça que conhecer a realidade de outros países é relevante para estimular uma reflexão crítica que cruze fronteiras.

A seguir apresentamos as análises curriculares sobre os conteúdos matemáticos presentes na BNCC envoltos a ideia de conhecimento e voz.

\section{Implicações das análises}

As reflexões ora apresentadas nos permitem inferir que as lutas que envolvem construções de conhecimento e o crescente poder de um novo bloco hegemônico a partir de uma aliança de forças direitistas que exercem lideranças na sociedade, têm a intenção de forçar a educação e tudo que é social, cultural e econômico para direções notavelmente conservadoras. Vimos também que as escolas precisam discutir mais detalhadamente as propostas curriculares a partir da BNCC (BRASIL, 2017) e os impactos do PNE (BRASIL, 2014), a fim de apontar uma relação entre as disputas educacionais presentes na BNCC e as metas propostas pelo PNE.

Sobre as decisões curriculares há limitações na autonomia docente, visto que não temos clareza se as questões sobre temas complexos como gênero, raça e religião, e a legitimidade de conhecimentos válidos, a partir da lente dos 'subalternos - os professores', compreendendo no que falaram e como falaram, e como os grupos dominantes reagiram a isso.

A BNCC apresenta dois rumos importantes os quais compreendem de um lado a formação inicial e continuada, e de outro lado a elaboração de materiais didáticos que envolvam as tecnologias digitais. É preciso esclarecer que para esses objetivos se efetivarem depende de muito investimento na formação docente e na infraestrutura das escolas.
Sobre os objetos de conhecimento do campo curricular de atemática nos anos iniciais do ensino fundamental, destacamos que é preciso maior importância de intercorrelação entre as unidades temáticas, a partir de objetivos que visem a [re]contextualização dos conteúdos curriculares com foco na realidade dos estudantes, promovendo uma aprendizagem de cunho significativo por meio de metodologias que visem a qualidade em detrimento da quantidade. Já os princípios norteadores entendemos que devem enfatizar melhor a relevância das metodologias e recursos didáticos, importantes para o desenvolvimento dos objetivos de aprendizagem, os quais ainda se apresentam vagos, insuficientes para nortear a composição de um currículo escolar de base nacional.

Devemos ficar atentos, pois por trás de um documento de BNCC há uma forte investida ideológica de um grupo direitista empenhado na supremacia de seus conhecimentos. Apple (2002b, p. 64), sobre isso faz uma pergunta: que grupo lidera tais reforços 'reformistas'? Não somos contra a uma BNCC, mas um documento com essa importância para ter sucesso deve ser elaborado de forma cooperativa mais abrangente, envolvendo a criação de um tecido articulador entre o social e o intelectual, a fim de conectar conteúdo x Pedagogia $\mathrm{x}$ currículo escolar. Ressaltamos, ainda, a importância de não se pensar em mudar a educação somente a partir de um documento sem a consciência de que é preciso maior investimento tanto nas escolas quanto na formação dos professores.

Embora a BNCC diga que garante o direito de aprendizagem dos componentes curriculares estabelecidos para toda a Educação Básica, a aprendizagem e desenvolvimento global do aluno, bem como a superação da fragmentação do conhecimento, o estímulo à sua aplicação no cotidiano, e que visa promover protagonismo do aluno em sua aprendizagem e a importância do contexto para dar sentido ao que se aprende, tais princípios subjacentes à $\mathrm{BNCC}$ precisam ser estudados pelos professores, na escola. Pois a interpretação in locus desse documento é de suma relevância para o combate ao neoconservadorismo e ao neoliberalismo. Visto que um busca resgatar um passado romantizado de lar, família e escola, e o outro, aposta no estado mínimo e amplo mercado, de todo modo, essas duas correntes pressupõem atualmente, uma política libertária dos propósitos econômicos, mas controladora nos propósitos sociais. 
Assim, enquanto uma aumenta liberdade de consumo, aumenta a desigualdade social, consequentemente, a outra reforça o sujeito vulnerável a mais controle social. É preciso que educadores fiquem atentos a essa polarização, pois temos de um lado escolas que servem ao mercado e de outro lado escolas mínimas.

A BNCC sobre o desenvolvimento dos conceitos matemáticos, destaca que são vistos como conhecimento legitimado para promover o desenvolvimento de muitas funções intelectuais, dentre elas (a) a atenção deliberada; (b) memória lógica; (c) abstração; e, (d) capacidade para comparar, objetivando desenvolver raciocínio lógico-matemático, e complementamos que os objetivos de aprendizagem devem servir para desenvolver conceitos matemáticos, e, principalmente, para a formação humanística dos estudantes. Mas, vale orientar nas escolas, professores e gestores, que sendo a BNCC um documento obrigatório é preciso que ao interpretá-la e executá-la observar que por trás das boas intenções de uma política de educação, está "um conjunto de tecnologias morais que trabalham em, dentro e por meio de instituições do setor público e de trabalhadores". (BALL, 2014, p. 65). E observe que, "[...] o contrato social dentro do qual o profissional trabalha, pelo interesse público, é substituído por relações comerciais entre educador, cliente e empregador". (BALL, 2014, 68-69). Ou seja, na concepção de Foucault $(1979$, p. 194) a política é substituída pela "sociedade mercantil", ou a mercantilização do conhecimento, deixando de ser a construção de ideais e passando a ser a construção de lucros e, portanto, questionamos: Qual conhecimento é útil aos interesses do capital?

\section{Para fim de conversa...}

Voltamos à pergunta do título do texto, mas ainda, sem resposta... Os subalternos falam? Nossa reflexão se apoia também em Gayatri Spivak (2014) quando apresenta o sujeito subalterno, e reforça que os subalternos não têm voz política ou se têm voz esta não é ouvida, e, mostra a importância do intelectual para abrir espaço de fala a este sujeito, mas evitando, nesse contexto, um possível etnocentrismo, porém possibilitando que ele seja ouvido.

De fato, as reflexões sobre um currículo nacional foram oficializadas no Brasil em 2017, a partir de um documento denominado Base Nacional Comum Curricular-BNCC. Sobre isso, este texto objetivou apresentar em que medida esse documento, a partir dos objetos de conhecimento, distribuídos em unidades temáticas, colaboram com o currículo de matemática, especialmente, para a matemática dos anos iniciais do ensino fundamental, considerando nesse contexto o direito de aprender a partir do desenvolvimento das habilidades.

Vimos que essas discussões se por um lado reforçam a necessidade das escolas de obterem orientações mais detalhadas para promover a inserção do debate no currículo local/regional e organizar melhor seu ensino. Por outro lado, as críticas contemplam a necessidade de mais autonomia para o professor realizar essa discussão na escola. Para tanto, Freire (1996) reforça que é preciso aprender a ser coerente, e de nada adianta o discurso competente se a ação pedagógica é impermeável às mudanças.

As políticas de currículo não devem só dar voz aos professores, mas devem também ouvi-los. Mas não é isso que ocorre, pois as escolas têm sido apenas o espaço de repositório de decisões das políticas curriculares reguladas por um estado avaliador que se utiliza de regulamentos e argumentos para: (a) distribuição de bônus; e, (b)ranqueamento das escolas, com a finalidade de conter os professores a rígidos controles, para garantir a efetividade das políticas públicas produzidas em instâncias administrativas que centralizam a educação. Pois "(...) a política que envolve produção, distribuição e recepção do conhecimento curricular é intensa e complexa, e as disputas pelo currículo - sobre quais experiências serão representadas como válidas ou qual língua ou história será ensinada - são constantes". (SANTOS; MATOS, 2017, p. 9).

Santos \& Matos (2017, p. 9), lembram que "as lutas pela hegemonia curricular concentram-se na produção e na distribuição do conhecimento [...]" $\mathrm{e}$ as escolas precisam funcionar "como locais de recontextualização do corpus formal desse conhecimento" (SANTOS; MATOS, 2017, p. 9).

As reformas curriculares historicamente, sempre foram cenário de muitas disputas, todavia faz-se relevante compreendermos, segundo Morin, (2003, p. 22) que "a reforma do ensino deve levar à reforma do pensamento, e a reforma do pensamento deve levar à reforma do ensino", e isso no mundo contemporâneo exige entender e documentar as inúmeras formas na qual as políticas educacionais são colocadas em ação nas escolas, e nos leva ao questionamento: qual é a relação do professor com a 
política curricular? Esperamos que essa relação seja mais pautada na reflexão que na flexibilização.

$E$ no que se refere ao currículo de matemática, envolvendo os objetos de conhecimentos e os direitos de aprendizagem, professores devem permanecer em luta pelo reconhecimento de um currículo, que não represente apenas a seleção de conteúdos, mas que seja uma construção cultural do sujeito, para o sujeito - na escola, num movimento de transformação do saber científico em saber escolar, com sentido na/para realidade desse sujeito.

Por toda essa necessidade de contínua discussão sobre o currículo, as reformas curriculares não cessam com a BNCC, mas esse documento inaugura uma nova era nas escolas básicas que incluem repensar a forma de ensinar e aprender, com implicações na formação docente, tendo em vista que é a primeira vez na história do Brasil que se elabora um currículo nacional de base comum.

\section{Notas}

1 Disponível em: https://novaescola.org.br/conteud $\mathrm{o} / 2850 /$ saviani-sobre-direitos-de-aprendizagemdocumento-e-mais-do-mesmo. Acesso dia 11 de junho de 2017.

2 Ativista político encarcerado na Itália fascista no final da década de 1920, usou essa palavra em seus cadernos de cárcere. Conferir em Apple \& Buras (2008, p. 12).

\section{Referências}

APPLE, M. W.; BURAS, K.L. Currículo, poder e lutas: com a palavra, os subalternos. Tradução Ronaldo Cataldo Costa. $1^{a}$ edição. Porto Alegre: Artmed, 2008.

APPLE, M. W. A política do Conhecimento oficial: faz sentido a ideia de um currículo nacional? In: MOREIRA, A. F. B.; SILVA, T. T. da (Orgs.). Currículo, cultura e sociedade. Tradução Maria Aparecida Baptista - 6. a edição - São Paulo, Cortez, 2002a. p. 59-91

APPLE, M. W. Repensando Ideologia e Currículo. In: MOREIRA, A. F. B.; SILVA, T. T. da (Orgs.). Currículo, cultura e sociedade. Tradução Maria Aparecida Baptista - 6. a edição - São Paulo, Cortez, 2002b. p. 39-58.
BALL, S. Diretrizes Políticas Globais e Relações Políticas Locais em Educação. CURRÍCULO SEM FRONTEIRAS. v. 1, n. 2, p. 99-116, 2001. Disponível

em: http://www.curriculosemfronteiras.org/vol1 iss2articl es/ball.pdf. Acesso em 06 de novembro de 2016.

BALL, S. Educação Global S.A.: Novas redes de políticas e o imaginário neoliberal. Tradução Janete Brindon. 23a edição. Ponta Grossa: Editora UEPA, 2014.

BERNSTEIN, B. A estruturação do discurso pedagógico: classe, código e controle. Tradução Tomaz Tadeu da Silva e Luís Fernando Gonçalves Pereira. Volume IV da edição original. Petrópolis, Editora Vozes, 1996.

BRASIL. Base Nacional Comum Curricular. $3^{\mathrm{a}}$ versão. Brasília: Ministério da Educação. 2017. Disponível em: http://basenacionalcomum.mec.gov.br/images/BNC C_20dez_site.pdf. Acesso em: 21 de março de 2018.

Plano Nacional de Educação (PNE, 20142024): Lei $\mathrm{n}^{\circ} 13.005$, de 25 de junho de 2014, que aprova o Plano Nacional de Educação (PNE) e dá outras providências. - Brasília: Câmara dos Deputados, Edições Câmara, 2014. 86 p. - (Série legislação; n. 125.

Lei de Diretrizes e Bases da Educação Nacional (LDBEN): Lei no. 9394/96. Brasília - DF, 1996.

Elementos conceituais e metodológicos para definição dos direitos de aprendizagem $e$ desenvolvimento do ciclo de alfabetização $\left(1 .^{\circ}, 2 .^{\circ} e\right.$ $3 .^{\circ}$ anos) do ensino fundamental, Brasília -DF, 2012. CURY, C. R. J. Direito à educação: direito à igualdade, direito à diferença. Cadernos de Pesquisa, n. 116, p. 245-262, julho/ 2002.

Constituição da República Federativa do Brasil de 1988. Brasília: Supremo Tribunal Federal, Secretaria de Documentação, 2017. 518 p. Atualizada até a EC n. 97/2017. Disponível em: http://www.stf.jus.br/arquivo/cms/legislacaoConstit uicao/anexo/CF.pdf. Acesso em 21 de março de 2018 .

D’AMBROSIO, U. Educação para uma Sociedade em Transição. $2^{\mathrm{a}}$ edição. Natal - RN: Editora da 
UFRN, 2011.

FOUCAULT, M. Microfísica do poder. Organização e tradução de Roberto Machado. $18^{\mathrm{a}}$ edição. Rio de Janeiro: Edições Graal, 1979.

FREIRE, P. Pedagogia da autonomia: saberes necessários à prática educativa. $16^{\mathrm{a}}$. edição. São Paulo: Paz e Terra, 1996.

FREIRE, P. Pedagogia do oprimido. $17^{\mathrm{a}}$ edição. Rio de Janeiro: Paz e Terra, 1987.

GRAMSCI, A. Concepção dialética da história. Tradução Carlos Nelson Coutinho. $4^{a}$ edição. Rio de Janeiro: Edições civilização brasileira, 1981.

MARCONI, M. A.; LAKATOS, E. M. Fundamentos de metodologia científica . $3^{\mathrm{a}}$ edição, São Paulo: Atlas, 1991. LOPES, A. C. A qualidade da escola pública: uma questão de currículo? In: VIANA, F. da S. [et all.] (Orgs.) A qualidade da escola publica no Brasil. $1^{\text {a }}$ edição. Belo Horizonte: Mazza edições, 2012.

LOPES, A. C.; MACEDO, E. Teorias de Currículo. $1^{a}$ edição. São Paulo: Cortez, 2011.

MORIN, E. A cabeça bem-feita: repensar a reforma, reformar o pensamento. $8^{\mathrm{a}}$ edição. Rio de Janeiro: Bertrand Brasil, 2003.

NÓVOA, A. Os Professores na Virada do Milênio: do excesso dos discursos à pobreza das práticas. Educação e Pesquisa. São Paulo, v. 25, n. 1, p. 1120, jan./jun. 1999.

SACRISTÁN, José Gimeno. (org.). Saberes $e$ incertezas sobre o currículo. Tradução: Alexandre Salvaterra. $1^{a}$ edição. Porto Alegre: Penso, 2013.

SANTOS, M. J. C., MATOS, F. C. C. A insubordinação criativa na formação contínua do pedagogo para o ensino da matemática: os subalternos falam? REnCiMa, v. 8, n. 4, p. 11-30, $2017 . \quad$ Disponível em: http://revistapos.cruzeirodosul.edu.br/index.php/ren cima/issue/view/59. Acesso: dia 21 de março de 2018 .

SAVIANI, D.. Pedagogia Histórico-Crítica: Primeiras Aproximações - $11^{\mathrm{a}}$ Edição. CampinasSão Paulo, 2013.

SPIVAK, G. C. Pode o subalterno falar? $1^{a}$ edição. Belo Horizonte: Editora UFMG, 2014. 2. ${ }^{a}$ Reimpressão.

\section{Sobre a autora}

Maria José Costa dos Santos: Professora na graduação e pós-graduação (PPGE/FACED/UFC). Desenvolve pesquisas com a Metodologia Sequência Fedathi, nas áreas de Educação Matemática, Formação matemática do professor do ensino fundamental, com foco no ensino e aprendizagem, currículo, avaliação. Discute a formação docente para a EJA, bem como, o uso de recursos didáticos tecnológicos. É líder do Grupo de Pesquisa Tecendo Redes Cognitivas de Aprendizagem(G-TERCOA/CNPq).

Recebido em novembro de 2017. Aprovado em março de 2018. 